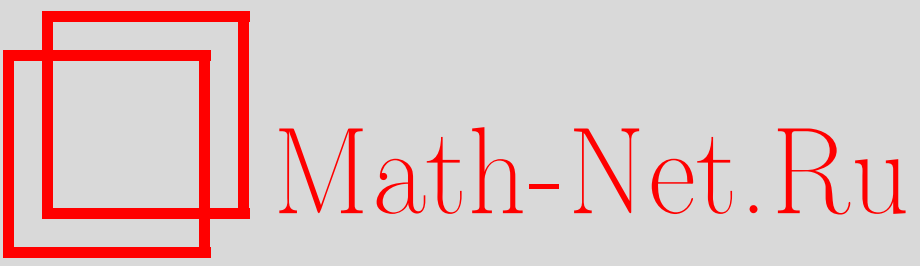

Л. А. Митлина, В. П. Гаврилин, М. Р. Виноградова, Г. С. Бадртдинов, Ю. В. Великанова, Влияние лазерного излучения на физические свойства монокристаллических пленок феррошпинелей, Вестн. Сам. гос. техн. ун-та. Сер. Физ.мат. науки, 2009, выпуск 1(), 198-205

DOI: https://doi.org/10.14498/vsgtu677

Использование Общероссийского математического портала Math-Net.Ru подразумевает, что вы прочитали и согласны с пользовательским соглашением http: //www. mathnet.ru/rus/agreement

Параметры загрузки:

IP: 54.224 .187 .69

26 апреля 2023 г., 04:33:05 
УДК 539.216.2:537.622.6

\title{
ВЛИЯНИЕ ЛАЗЕРНОГО ИЗЛУЧЕНИЯ НА ФИЗИЧЕСКИЕ СВОЙСТВА МОНОКРИСТАЛЛИЧЕСКИХ ПЛЁНОК ФЕРРОШПИНЕЛЕЙ
}

\author{
Самарский государственный технический университет, \\ 443100, Самара, ул. Молодогвардейская, 244. \\ Самарский государственный педагогический университет, \\ 443099, г. Самара, ул. М. Горького, 65/67. \\ E-mail: physics@samgtu.ru
}

Л. А. Митлина ${ }^{1}$ В. П. Гаврилин ${ }^{2}$, М.Р. Виноградова ${ }^{1}$ Е. А. Косарева ${ }^{1}$, Г. С. Бадртдинов ${ }^{1}$, Ю. В. Великанова

Показана возможность использования лазерного воздействия для уменъшения магнитных потерь, изменения полей анизотропии, внутренних напряжений, электропроводности, микропрочности монокристаллических плёнок марганиевых феррошпинелей.

Ключевые слова: плёнки феррошпинелей, лазерное облучение, прочность, внутренние напряжения, электропроводность, поле анизотропии, магнитные потеpu.

Введение. Характерной особенностью современных технологий производства изделий из металлов и сплавов являются импульсные методы лазерной обработки. Эти методы характеризуются приложением высокой удельной энергии, её импульсным воздействием на относительно малые объёмы твердого тела и последующим охлаждением с большими скоростями, что приводит к формированию на поверхности материалов специфических структур с особыми физико-механическими свойствами [1].

Цель настоящей работы заключалась в исследовании влияния лазерного облучения на температурные зависимости электропроводности, зависимость микротвёрдости от глубины внедрения индентора, резонансные параметры монокристаллических плёнок марганцевых феррошпинелей и анализа экспериментальных результатов исходя из существующих теорий и моделей.

При выборе химического состава феррошпинелей исходили из потенциальных возможностей практического применения данной группы феррошпинелей в СВЧ-устройствах из-за высокой намагниченности и больших полей анизотропии.

Объекты и методы исследования. В качестве объектов исследования были выбраны монокристаллические плёнки исходного состава $\mathrm{Mn}_{x} \mathrm{Fe}_{3-x} \mathrm{O}_{4}(x=1$;

Митлина Людмила Александровна - профессор кафедры общей физики и физики нефтегазового производства; д.ф.-м.н., профессор.

Гаврилин Валерий Павлович - дочент кафедры теоретической физики; к.ф.-м.н., дочент. Виноградова Маргарита Рудольфовна - дочент кафедры общей физики и физики нефтегазового производства; к.ф.-м.н.

Косарева Евгения Александровна - доцент кафедры общей физики и физики нефтегазового производства; к.ф.-м.н.

Бадртдинов Григорий Сайдашевич - ассистент кафедры общей физики и физики нефтегазового производства.

Великанова Юлия Владимировна - доцент кафедры общей физики и физики нефтегазового производства; к.фб.-м.н. 
$0,65) \mathrm{Mg}_{x} \mathrm{Mn}_{1-x} \mathrm{Fe}_{2} \mathrm{O}_{4}(x=0,4 ; 0,6 ; 0,8)$.

Монокристаллические плёнки получены методом химических транспортных реакций на свежих сколах (001) оксида магния.

По данным рентгенографического и микроструктурного анализов все исследуемые образцы однофазны и имеют структуру шпинели. Исследования спектров ферромагнитного резонанса (ФМР) проводились на полуавтоматизированной установке в 3-сантиметровом диапазоне длин волн.

Электросопротивление измерялось с помощью моста МОД-61.

Исследование микротвёрдости проводились на приборе ПМТ-3М путём вдавливания алмазной пирамидки Виккерса. Все измерения проводились в идентичных условиях: время нагружения, выдержки и снятия нагрузки составляло 10 с. Микротвёрдость плёнок феррошпинелей вычислялась по формуле [2]

$$
H=\frac{1854 P}{d^{2}}
$$

где $P$ - прикладываемая нагрузка, $d$ - диагональ отпечатка.

Плёнки феррошпинелей облучались двумя способами:

- непрерывным излучением лазера на неодимовом стекле $(h \nu \sim 1,17$ эВ, $\lambda \sim 1,06$ мкм) мощностью от 20 до 30 Вт;

- импульсным облучением лазера на парах меди длительностью 10 мс с длиной волны $\lambda \sim 0,7$ мкм.

Результаты эксперимента и их обсуждение. Возникновение в объёмных ферритах точечных дефектов - катионных и анионных вакансий - вызывается различными причинами [3]. Прежде всего, тип вакансий определяется химическим составом феррита. Ферриты шпинелей стехиометрического состава имеют общую формулу $\mathrm{Mn}^{2+} \mathrm{Fe}^{3+} \mathrm{O}_{4}^{2-}$, где отношение катионов к числу анионов составляет $3 \div 4$. Если отношение количества катионов $\left(N_{\mathrm{K}}\right)$ и анионов $\left(N_{\mathrm{a}}\right)$, составляющих феррит, не равно $3 \div 4$, в нём возникает дефектность по кислороду: $\frac{N_{\mathrm{K}}}{N_{\mathrm{a}}}=\frac{3}{4 \pm \gamma}$. При $+\gamma$ в ферритах присутствуют избыточные катионные вакансии, а при $-\gamma-$ анионные вакансии и дефекты типа «внедрённые катионы». При избытке $\mathrm{Fe}_{2} \mathrm{O}_{3}$ должны возникать катионные вакансии. Избыток $\mathrm{MeO}$ вызывает появление анионных вакансий или внедренных катионов.

В плёнках феррошпинелей могут возникать вакансии и внедренные атомы вследствие пластической деформации при гетероэпитаксии феррита на окись магния и последующего охлаждения [4-6].

При используемой технологии получения плёнок феррошпинелей закалка производится при температуре $T \sim(700 \div 800) \mathrm{K}$. Равновесная концентрация тепловых вакансий задаётся соотношением [7]:

$$
n_{\text {вак }}=N_{0} \exp \left(-\frac{\varepsilon_{\mathrm{v}}}{k T}\right),
$$

где $\varepsilon_{\mathrm{v}}$ - энергия образования вакансии, $N_{0} \sim 2,7 \cdot 10^{28} \mathrm{M}^{-3}$ - число узлов в $1 \mathrm{~m}^{3}$. Энергия образования анионной вакансии в ферритах $\sim 0,78$ эВ, а катионной $-\sim 0,6$ эВ [3]; ожидаемая концентрация вакансий в плёнках феррошпинелей при $(700 \div 800) \mathrm{K}$ - порядка $10^{23} \mathrm{M}^{-3}$. Если осуществить быстрое охлаждение плёнок до комнатной температуры, то вакансии не смогут продиффундировать к имеющимся стокам, и значительное число их «заморозится». Кроме того, при охлаждении кристалла из-за термических напря- 
жений происходит дополнительная генерация точечных дефектов. В плёнках магний-марганцевого феррита при относительной деформации $\varepsilon \sim 10^{-3}$ возможно образование вакансий $\sim 10^{22} \mathrm{M}^{-3}$, в плёнках марганцевого феррита при $\varepsilon \sim 10^{-2}$ - концентрация вакансий $\sim 10^{23} \mathrm{M}^{-3}$.

По данным кинетических явлений [5], в плёнках феррошпинелей содержатся химические примеси с относительной концентрацией $\sim 10^{-3}$ для исходного состава $\mathrm{MnFe}_{2} \mathrm{O}_{4}$ и $\sim 10^{-2} \div 10^{-1}$ для составов $\mathrm{Mg}_{0,6} \mathrm{Mn}_{0,4} \mathrm{Fe}_{2} \mathrm{O}_{4}$ и $\mathrm{Mg}_{0,8} \mathrm{Mn}_{0,2} \mathrm{Fe}_{2} \mathrm{O}_{4}$.

Структурные изменения при облучении определяются свойствами точечных дефектов. Основным параметром, который определяет поведение точечных дефектов, является энергия образования. Оценим энергию образования точечных дефектов из измерений электросопротивления при облучении лазером различной мощностью, полагая, что будут преобладать те дефекты, для образования которых требуется меньшая энергия, т.е. катионные вакансии. Мощность лазерного излучения поглощается полупроводниковым материалом по закону Бугера-Ламберта [8]:

$$
\Delta P(z)=(1-R) P[1-\exp (-\gamma z)],
$$

где $\Delta P(z)$ - поглощение на глубине, $P$ - мощность падающего на образец облучения, $R \sim 0,3$ - коэффициент отражения, $\gamma \sim 1,7 \cdot 10^{4} \mathrm{~cm}^{-1}$ - коэффициент поглощения [9]. При таком коэффициенте поглощения $e^{-\gamma z} \sim 0$, т. е. практически вся падающая энергия поглощается плёнкой.

В случае $P \sim(20-30)$ Вт мощность излучения была недостаточна для плавления, и плёнки разогревались до температуры $T \sim(520-780) \mathrm{K}$. Температура разогревания определялась по формуле

$$
T=\frac{P}{\pi r \lambda}
$$

где $R=2,5 \cdot 10^{-3}$ м - радиус светового пятна, $\lambda=3,44 \mathrm{Bт} /(\mathrm{м} \cdot \mathrm{K})-$ коэффициент теплопроводности Mn-феррита.

При обработке лазером, работающем в непрерывном режиме, механизм образования точечных дефектов сходен с обычным термическим. Поэтому, измерив изменение удельного сопротивления $\Delta \rho$ как функцию температуры закалки, можно найти по тангенсу угла наклона $\ln \Delta \rho=f\left(\frac{1}{T}\right)$ энергию активации точечных дефектов. Для плёнок Mn-ферритов она оказалась равной $\sim 0,6$ эВ, что ниже энергии образования анионной вакансии [3], где $\varepsilon_{\mathrm{v}} \sim 0,78$ эВ. Это даёт возможность считать, что при облучении лазером рассматриваемой мощности в ферритовых плёнках происходит генерация катионных вакансий. При закалке в кристалл вводится определённая концентрация точечных дефектов, которая в случае бесконечно быстрого охлаждения стремится к пределу, определяемому равновесной концентрацией этих дефектов при температуре, от которых производится закалка. При любой температуре $T$ равновесная концентрация вакансий задается соотношением (1). Используя значения для $\varepsilon_{\mathrm{v}} \sim 0,6$ эВ, получим пересыщение вакансиями при закалке от температур $T \sim(520-780) \mathrm{K}$ порядка $(1-2) \cdot 10^{10}$ по отношению к равновесной концентрации при комнатной температуре. 
На рис. 1 представлены зависимости $\ln \rho=f\left(\frac{1}{T}\right)$. Из графиков видно, что при облучении мощностью 30 Вт происходит увеличение степени размытости фазового превращения в области температуры Кюри с изменением скачка сопротивления. После данной обработки увеличивается электропроводимость, параметр обменного взаимодействия, изменяется энергия активации носителей тока. Наибольшее изменение энергии активации проводимости наблюдается при низких температурах (табл. 1).

По данным [3], уменьшение энергии активации при низких температурах может быть связано с переходом $\mathrm{Fe}^{3+} \rightarrow$ $\mathrm{Fe}^{2+}$. Переход связан с окислительновосстановительным равновесием:

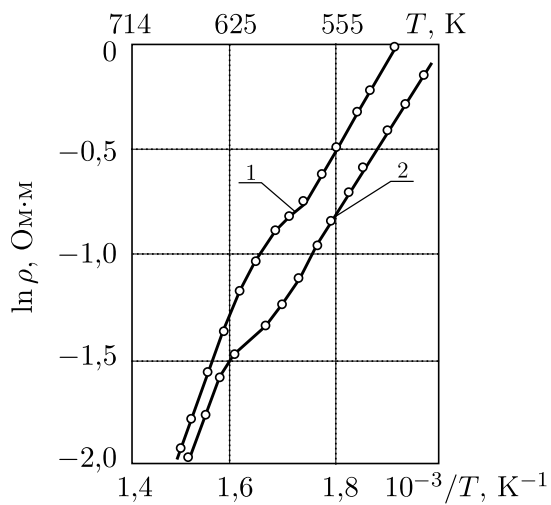

Рис. 1. Зависимость $\ln \rho=$ $=f\left(\frac{1}{T}\right)$ для плёнок $\mathrm{Mn}$ феррита в области температуры Кюри до облучения лазером (1), поосле облучения (2) при мощности облучения $30 \mathrm{BT}$

$$
\mathrm{Mn}^{2+}|B|+\mathrm{Fe}^{3+}|B| \rightleftarrows \mathrm{Mn}^{3+}|B|+\mathrm{Fe}^{2+}|B| .
$$

Возникающие благодаря этому дополнительные ионы $\mathrm{Fe}^{2+}$, вступая в реакцию

$$
9 \mathrm{Fe}^{2+}|B|+2 \mathrm{O}_{2} \rightleftarrows 6 \mathrm{Fe}^{3+}|B|+\mathrm{Fe}_{3} \mathrm{O}_{4}+3|B|,
$$

увеличивают дефектность структуры с образованием катионных вакансий $(|B|$ - обозначение октаэдрических узлов решётки).

В работе [10] теоретически обосновано существования излома на кривых $\ln \rho=f\left(\frac{1}{T}\right)$. При переходе через температуру Кюри энергия активации и эффективная масса носителей в ферромагнитных полупроводниках благодаря $s-d$-обменному взаимодействию зависят от самопроизвольной намагниченности. Величина излома тем больше, чем сильнее обменное взаимодействие. Увеличение параметра обменного взаимодействия после облучения лазером может быть обусловлено механизмом косвенного обмена через электроны проводимости, связанные с дефектностью структуры. В частности, переход $\mathrm{Fe}^{2+} \rightarrow \mathrm{Fe}^{3+}$ приводит к усилению обменного взаимодействия [3].

Процессы упругопластического деформирования и хрупкого разрушения

Т аб лиц а 1

\begin{tabular}{|c|c|c|c|c|c|}
\hline \multirow{2}{*}{$\begin{array}{l}\text { Мощ- } \\
\text { ность } \\
\text { облу- } \\
\text { чения } \\
P, \text { Вт }\end{array}$} & \multirow{2}{*}{$\begin{array}{c}\text { Удельное } \\
\text { сопротив- } \\
\text { ление при } \\
\text { комнатной } \\
\text { температуре } \\
\rho, \text { Ом·м }\end{array}$} & \multicolumn{3}{|c|}{$\begin{array}{c}\text { Энергия активации в различных } \\
\text { температурных интервалах }\end{array}$} & \multirow{2}{*}{$\begin{array}{c}\text { Параметр } \\
\text { обменного } \\
\text { взаимодей- } \\
\text { ствия } \\
\beta, \text { эВ }\end{array}$} \\
\hline & & $\begin{array}{c}\Delta E_{1} \\
(130-220) \mathrm{K}\end{array}$ & $\begin{array}{c}\Delta E_{2} \\
(350-500) \mathrm{K}\end{array}$ & $\begin{array}{c}\Delta E_{3}, \\
(660-860) \mathrm{K}\end{array}$ & \\
\hline- & 820 & 0,29 & 0,39 & 0,52 & 0,13 \\
\hline 20 & 695 & 0,25 & 0,3 & 0,53 & 0,14 \\
\hline- & 470 & 0,28 & 0,38 & 0,54 & 0,16 \\
\hline 30 & 210 & 0,25 & 0,35 & 0,53 & 0,18 \\
\hline
\end{tabular}

Параметры плёнок феррошпинелей до и после лазерного облучения 
при микровдавливании описываются степенными функциями [2]:

$$
P=a d^{n}, \quad P=b D^{m},
$$

где $a$-размерный коэффициент, характеризующий прочностные свойства испытуемого материала; $n$ - безразмерный коэффициент, характеризующий интенсивность процесса упругопластического деформирования материала при вдавливании индентора; $b$ - размерный коэффициент, характеризующий хрупкие свойства материала; $m$ - безразмерный коэффициент, характеризующий интенсивность хрупкого разрушения материала в области отпечатка. Из сопоставления полученных данных (рис. 2 а и 2 б) следует, что лазерное облучение в атмосфере воздуха в режиме непрерывной генерации приводит к росту интенсивности упругопластического деформирования на $4-7 \%$ и к уменьшению интенсивности хрупкого разрушения на $18 \%$.
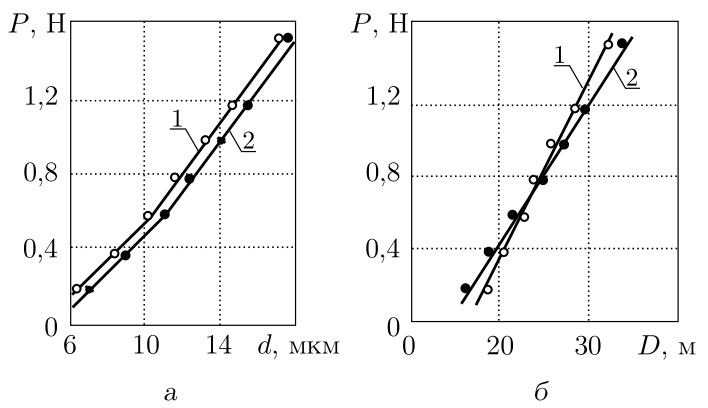

Рис. 2. Зависимость длины диагонали отпечатка (а) и зоны хрупкой повреждаемости (б) от нагрузки на индентор для плёнок состава $\mathrm{MnFe}_{2} \mathrm{O}_{4}$ толщиной 12 мкм: 1 - до облучения, 2-после лазерного облучения в атмосфере воздуха

Сравнительный анализ исследуемых образцов (см. рис. 3) показывает, что для плёнок феррошпинелей поведение поверхностного слоя при деформировании индентором отличается от поведения внутренних объёмов материала. В области нагрузок $(0,78-1,47)$ Н при уменьшении диагонали отпечатка и толщины поверхностных слоёв наблюдается линейный рост микротвёрдости, что не противоречит результатам исследования объёмных ферритов [2]. В области малых нагрузок $(0,2-0,78) \mathrm{H}$ микротвёрдость уменьшается.

Следуя [11], можно предположить, что при микровдавливании монокристаллических плёнок феррошпинелей темп роста микротвёрдости на начальной стадии деформации будет определяться аномалиями течения поверхностных слоев, т. е. темпом роста плотности дислокаций в поверхностных слоях. Глубина поверхностного слоя убывает в зависимости от исходного химического состава в соответствии с ростом концентрации химических примесей. Самый низкий темп роста микротвёрдости наблюдается для плёнок исходного состава $\mathrm{Mg}_{0,8} \mathrm{Mn}_{0,2} \mathrm{Fe}_{2} \mathrm{O}_{4}$, где, по данным кинетических изменений [5], содержится самая высокая концентрация химических примесей $\left(10^{27} \mathrm{M}^{-3}\right)$. После лазерного облучения в атмосфере воздуха для плёнок марганцевого феррита (рис. 4) наблюдается уменьшение глубины поверхностного слоя. При этом на глубине $0,8 \div 1,3$ мкм микротвёрдость увеличивается, а на $1,3 \div 2,0$ мкмуменьшается, что не противоречит данным [1]. Лазерные обработки матери- 


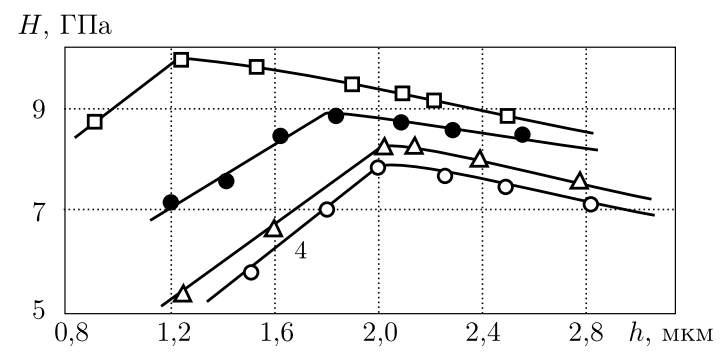

Рис. 3. Зависимость микротвердости от глубины внедрения индентора для плёнок толщиной 25-30 мкм исходного состава: $\mathrm{MgMn}_{1-x} \mathrm{Fe}_{2} \mathrm{O}_{4}$ с $x=0,8$ (1); 0,6 (2); 0,4 (3); 0 (4)

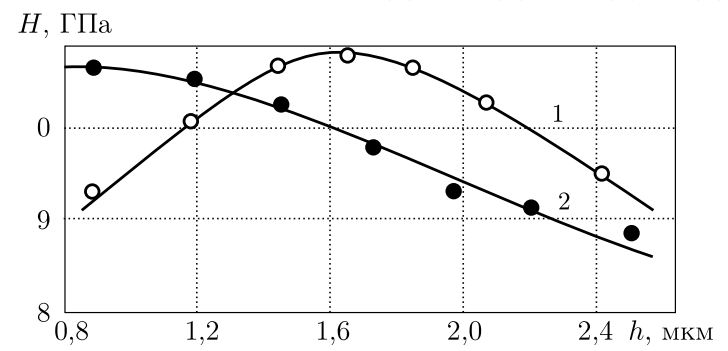

Рис. 4. Зависимость микротвердости от глубины внедрения индентора для плёнок состава: $\mathrm{MnFe}_{2} \mathrm{O}_{4}$ толщиной 12 мкм: 1 - до облу-

чения 2 - после лазерного облучения в атмосфере воздуха

алов могут приводить к упрочнению поверхностного слоя и отпуску более глубоких слоев.

Основными параметрами, определяющими пригодность использования ферритовых материалов для СВЧ-техники, являются эффективная намагниченность, поля резонанса, поля анизотропии, магнитные потери. Представляет интерес рассмотрение влияния лазерного облучения для изменения этих параметров. Анализируя данные табл. 2, можно видеть, что лазерное облучение в режиме непрерывной генерации (образцы $1,2,3$ ) позволяет снизить магнитные потери до $50 \%$, увеличить время релаксации. Наибольший эффект $(50 \%)$ наблюдается для исходного состава $\mathrm{Mn}_{x} \mathrm{Fe}_{3-x} \mathrm{O}_{4}(x=1)$.

Эффективный параметр затухания $\alpha$, характеризующий магнитные по-

Таблица 2

Резонансные параметры $(f=9,44$ ГГц) плёнок феррошпинелей исходного состава $\mathrm{Mn}_{x} \mathrm{Fe}_{3-x} \mathrm{O}_{4}$ до и после облучения лазером

\begin{tabular}{c|c|c|c|c|c|c|c}
\hline \multirow{2}{*}{$\begin{array}{c}\text { № об- } \\
\text { раз- } \\
\text { ца }\end{array}$} & $\begin{array}{c}\text { Исходный } \\
\text { химичес- } \\
\text { кий сос- } \\
\text { тав, } x\end{array}$ & $\begin{array}{c}\text { Резо- } \\
\text { нанс- } \\
\text { ное } \\
\text { поле }\end{array}$ & $\begin{array}{c}\text { Эффек- } \\
\text { тивный } \\
\text { коэф. } \\
\text { зату- } \\
\text { хания }\end{array}$ & $\begin{array}{c}\text { Эффек- } \\
\text { время } \\
\text { релак- } \\
\text { сации }\end{array}$ & $\begin{array}{c}\text { Резо- } \\
\text { нанс- } \\
\text { ное } \\
\text { поле }\end{array}$ & $\begin{array}{c}\text { Эффек- } \\
\text { тивный } \\
\text { коэф- } \\
\text { зату- } \\
\text { хания }\end{array}$ & $\begin{array}{c}\text { Эффек- } \\
\text { тивное } \\
\text { время } \\
\text { релак- } \\
\text { сации }\end{array}$ \\
\cline { 3 - 8 } & & $\begin{array}{c}H_{\mathrm{p}[100]}, \\
\vartheta\end{array}$ & $\alpha \cdot 10^{2}$ & $\tau \cdot 10^{10}$ & $H_{\mathrm{p}[100]}$, & $\alpha \cdot 10^{2}$ & $\tau \cdot 10^{10}$ \\
\hline 1 & 0,65 & 2092 & 1,38 & 6,0 & 2075 & 1,16 & 7,30 \\
2 & 0,65 & 2171 & 1,15 & 7,3 & 2135 & 7,90 & 1,07 \\
3 & 1 & 2155 & 1,39 & 6,1 & 2145 & 6,90 & 1,22 \\
4 & 065 & 2098 & 119 & 71 & 2298 & 2,10 & 4,0 \\
\hline
\end{tabular}


тери, определяется величиной $\alpha=\frac{\Delta H}{H_{\mathrm{p}}}$, где $\Delta H$ - полуширина резонансной кривой, $H_{\mathrm{p}}$ - резонансное поле. Здесь $\tau=\frac{1}{\alpha \omega}-$ эффективное время релаксации, $\omega$ - частота, на которой проводилось исследование.

После лазерного облучения в импульсном режиме $(\lambda=0,7$ мкм, $t=10 \mathrm{мc}$, образец 4) эффективные магнитные потери увеличиваются, а эффективное время релаксации уменьшается.

Изменение резонансных параметров по легкой $H_{\mathrm{p}[110]}$ и трудной $H_{\mathrm{p}[100]}$ осям позволяет оценить поле анизотропии и внутренние напряжения по методике, изложенной в работе [12] и используемой также в работе [13] (табл. 3).

Таблица 3

Резонансные параметры, поле анизотропии и внутренние напряжения в плёнках феррошпинелей исходного состава $\mathrm{Mn}_{x} \mathrm{Fe}_{3-x} \mathrm{O}_{4}$ до и после облучения лазером

\begin{tabular}{|c|c|c|c|c|c|c|c|c|}
\hline \multirow{3}{*}{$\begin{array}{l}\text { № об- } \\
\text { раз- } \\
\text { ца }\end{array}$} & \multicolumn{4}{|c|}{ До облучения } & \multicolumn{4}{|c|}{ После облучения } \\
\hline & \multicolumn{2}{|c|}{$\begin{array}{l}\text { Резонанс- } \\
\text { ные поля }\end{array}$} & \multirow{2}{*}{$\begin{array}{c}\text { Поле } \\
\text { анизо- } \\
\text { тропии } \\
H_{a} \\
\vartheta\end{array}$} & \multirow{2}{*}{ 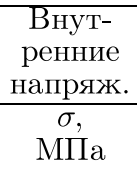 } & \multicolumn{2}{|c|}{$\begin{array}{l}\text { Резонанс- } \\
\text { ные поля }\end{array}$} & \multirow{2}{*}{$\begin{array}{c}\text { Поле } \\
\text { анизо- } \\
\text { тропии } \\
H_{a}, \\
\ni\end{array}$} & \multirow{2}{*}{ 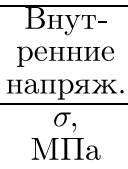 } \\
\hline & $H_{\stackrel{y}{[100]}}$, & $H_{\underset{\vartheta}{[110]}}$, & & & 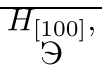 & $H_{\frac{1110]}{y}}$, & & \\
\hline 1 & 2171 & 1746 & 340 & 607 & 2135 & 1728 & 326 & 745 \\
\hline 2 & 2092 & 1610 & 385 & 518 & 2077 & 1611 & 372 & 606 \\
\hline 3 & 2155 & 1844 & 249 & 158 & 2143 & 1845 & 238 & 141 \\
\hline 4 & 2098 & 1721 & 302 & 42 & 2286 & 1834 & 362 & 215 \\
\hline
\end{tabular}

Расчёты показали, что лазерное воздействие приводит:

- в режиме непрерывной генерации - к уменьшению поля анизотропии $(4 \div 20) \%$, росту внутренних напряжений $\sim(17 \div 23) \%$;

- в импульсном режиме - к росту поля анизотропии на $\sim 20 \%$ и напряжений в $\sim 4$ раза.

Таким образом, анализ представленных результатов указывает на перспективность использования лазерного воздействия с целью улучшения эксплуатационных характеристик для СВЧ-устройств монокристаллических плёнок феррошпинелей, таких как магнитные потери, время релаксации, резонансные поля и магнитная анизотропия. Изменение при поглощении лазерного излучения физических свойств плёнок возможно за счет генерации неравновесных носителей заряда, внутреннего фотоэффекта, т. к. $h \nu>\Delta E$, тепловых эффектов с поглощением кислорода, последующего изменения валентного состояния ионов и их перераспределения по узлам решётки.

\section{БИБЛИОГРАФИЧЕСКИЙ СПИСОК}

1. Гуреев Д. М., Ямщиков С. В. Основы физики лазеров и лазерной обработки материалов. - Самара: Самарский университет, 2001. - 392 с.

2. Бердников В. Ф., Пушкарев О. И., Гавриченко В. В. Исследование анизотропии механических свойств монокристаллов ферритов методом микровдавливания // Пробл. прочности, 1985. - № 7. - С. 67-70.

3. Летюк Л.М., Журавлев Г.И. Химия и технология ферритов. - Л: Химия, 1983. $255 \mathrm{c}$.

4. Митлина Л. А., Виноградова М. Р., Янковская Т. В. Основные закономерности упругопластичного и хрупкого разрушения эпитаксиальных феррошпинелей // Вестн. Сам. гос. техн. ун-та. Сер. Физ.-мат. науки, 2004. - № 26. - С. 141-150.

5. Митлина Л. А., Харламов А. Д., Колосова И. В., Левин А. Е. Структурные дефекты и явления переноса в эпитаксиальных феррошпинелях // Вестн. Сам. гос. техн. ун-та. Сер. Физ.-мат. науки, 1998. - №6. - С. 47-54. 
6. Митлина Л. А. Физико-химические основы получения, дефектность стуктуры и свойства монокристаллических плёнок феррошпинелей // Вестн. Сам. гос. техн. ун-та. Сер. Физ.-мат. науки, 2004. - № 30. - С. 114-149.

7. Родэс Р. Г. Несовершенства и активные центры в полупроводниках. - М: Металлургия, 1963. - $371 \mathrm{c}$.

8. Готра З.Ю., Осенедко С.А., Бобицкий Я.В. Импульсный лазерный отжиг ионноимплантированных полупроводниковых материалов // 3ЭТ, 1983. - № 6. - С. 3-64.

9. Кошкин Л.И., Березин Д. Г., Бирюкова Л. Н., Дубенская Н. Е., Дунаева Т. А. Исследования края оптического поглощения ферритовых плёнок / В сб.: Исследования по физике ферритов и электроники. - №67. - Куйбышев: КПИ, 1969. - С. 15-20.

10. Туров Е.А., Ирхин Ю.П. К феноменологической теории электропроводности ферритов и антиферромагнетиков / В сб.: Ферриты: Доклады III Всесоюзного совещания по физическим физико-химическим свойствам ферритов и физическим основам их применения. - АН БССР: Минск, 1960. - С. 7-19.

11. Алехин В. П. Физика прочности и пластичности поверхностных слоев материалов. М: Наука, 1983.

12. Березин Д. Г., Гаврилин В. П. О природе одноосной анизотропии в монокристаллических плёнках Li феррита / B сб.: Магнетизм и электроника (ферритовые плёнки). № 104, 1982. - C. 141-144.

13. Митлина Л.А., Сидоров А.А., Бадртдинов Г. С. Несовершенство структуры, магнитные и СВЧ свойства монокристаллических плёнок марганцевых феррошпинелей // Вестн. Сам. гос. техн. ун-та. Сер. Физ.-мат. науки, 2008. - №1(16). - С. 136-140.

Поступила в редакцию 11/II/2009;

в окончательном варианте - 29/II/2009.

MSC: 82D40, 82D25, 74K35

\title{
INFLUENCE OF LASER RADIATION ON PHYSICAL PROPERTIES OF MONOCRYSTAL FILMS FERROSHPINELES
}

\author{
L. A. Mitlina ${ }^{1}$, V.P. Gavrilin ${ }^{2}$, M. R. Vinogradova ${ }^{1}$, \\ E. A. Kosareva ${ }^{1}$, G.S. Badrtdinov ${ }^{1}, Y u . V$. Velikanova ${ }^{1}$ \\ 1 Samara State Technical University, \\ 244, Molodogvardeyskaya str., Samara, 443100. \\ 2 Samara State Teacher's Training University, \\ 65/67, M. Gorkogo str., Samara, 443099, . \\ E-mail: physics@samgtu.ru
}

Possibility of use of laser influence for reduction of magnetic losses, change of fields of anisotropy, internal pressure, electroconductivity, microdurabilities of monocrystal films manganous ferroshpineles is shown.

Key words: ferroshpineles films, laser influence, durability, internal pressure, electroconductivity, fields of anisotropy, magnetic losses.

Original article submitted 11/II/2009; revision submitted $29 / \mathrm{II} / 2009$.

Mitlina Lyudmila Alexandrovna, Dr. Sci. (Phys. \& Math.), Prof., Dept. of General Physics. Gavrilin Valeriy Pavlovich, Ph.D. Phis. (Phys. ES Math.), Ass. Prof., Dept. of Theoretical Physics.

Vinogradova Margarita Rudolfovna, Ph.D. Phis. (Phys. $\& 3$ Math.), Ass. Prof., Dept. of General Physics.

Kosareva Evgeniya Alexandrovna, Ph. D. Phis. (Phys. \& Math.), Dept. of General Physics. Badrtdinov Gregori Saidashevich, Assist., Dept. of General Physics.

Velikanova Yuliya Vladimirovna, Ph.D. Phis. (Phys. ES Math.), Dept. of General Physics. 